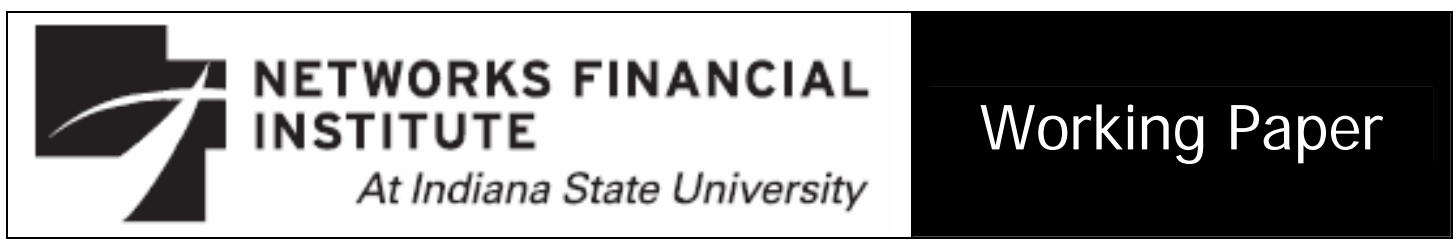

2007-WP-11

March 2007

\title{
Repayment Performance in Microcredit Programs: Theory and Evidence
}

\section{Joel M. Guttman}

\begin{abstract}
This paper revisits the conventional wisdom on the determinants of the success of microcredit programs. The paper first develops a simple moral hazard model of borrowing in a group lending context, and then tests this model using data from a survey conducted in Bangladesh in 1991-92. One of the predictions of the moral hazard model, regarding the effect of group size on repayment performance, is rejected by the empirical evidence. The paper then develops an alternative approach, which is consistent with the observed effect of group size as well as the other empirical results.
\end{abstract}

About the Author: Joel M. Guttman is a Senior Fellow at Networks Financial Institute. Guttman is currently serving as an associate professor in the department of economics in Bar-Ilan University. He has also served as a visiting professor at the University of Chicago, Brown University and the Helsinki School of Economics. His research areas include evolution of trust and cooperation, economic growth and conflict (internal and external), public economics, applied game theory, and defense economics. He has published numerous articles in scholarly journals including American Economic Review, Journal of Political Economy, Journal of Public Economics, and Economic Journal. He received his Ph.D. in economics from the University of Chicago.

Keywords: microfinance, microcredit, group lending

The views expressed are those of the individual author and do not necessarily reflect official positions of Networks Financial Institute. Please address questions regarding content to Joel M. Guttman at guttman@mail.biu.ac.il. Any errors or omissions are the responsibility of the author.

NFI working papers and other publications are available on NFI's website (www.networksfinancialinstitute.org). Click "Research" and then "Publications/Papers." 


\section{Repayment Performance in Microcredit Programs: Theory and Evidence}

\section{Joel M. Guttman*}

\section{Introduction}

The introduction of microcredit in Bangladesh in the mid-1970s is widely regarded as one of the most important innovations in development policy in the last fifty years. Microcredit is the system of providing small loans to poor households, generally utilizing group liability as a tool to stimulate repayment of the loans. The widespread enthusiasm for microcredit is reflected in the awarding of the 2006 Nobel Peace Prize to Muhammed Yunus, the founder of the Grameen Bank and the major innovator of microcredit. High repayment rates - generally on the order of 95 percent - and the millions of borrowers in microcredit programs around the world, are two reasons for the widely perceived success of this innovation.

Theoretical studies of microcredit by economists have focused on the reasons for the success of microcredit in comparison to more traditional systems for delivering credit. All three of the main explanations (which are discussed further in Section 2) locate the advantages of microcredit in the group liability structure that generally characterizes microcredit programs. In parallel to these theoretical studies, there have been a number of empirical studies that test hypotheses relating to the determinants of repayment performance in microcredit programs. ${ }^{1}$

The present paper develops a simple model that formalizes one of the three existing explanations for the success of microcredit. This model is tested with data from a survey conducted in Bangladesh in 1991-2. One of the empirical findings - regarding the effect of group size on repayment performance - contradicts the effect of group size predicted by the theoretical model. I then argue that this empirical result is much more easily explained if an alternative explanation for the success of microcredit is adopted.

\footnotetext{
*Department of Economics, Bar-Ilan University, 52900 Ramat-Gan, Israel, and Senior Fellow, Networks Financial Institute. E-mail: guttman@mail.biu.ac.il. I thank Mark Pitt for providing the data on which this study is based, and the Networks Financial Institute for funding the research.

${ }^{1}$ For general surveys of the theoretical and empirical literature, see Ghatak and Guinnane (1999), Morduch (1999), and Guttman (2006b).
} 
Repayment Performance in Microcredit Programs: Theory and Evidence 2

\section{A Benchmark Model}

\subsection{Background}

There are three basic characteristics of microcredit programs, as exemplified by the Grameen Bank, which need to be kept in mind when analyzing such programs:

1. Joint liability. Loans are provided to individuals who belong to a group. Group members are held responsible for the repayment of their peers' debts. Perhaps the most powerful incentive employed to ensure joint liability is the threat that if one of the group members defaults, the remaining members will not receive loans in the future, unless they arrange for repayment of the defaulter's debt.

2. Small installment payments. In traditional Grameen Bank loans, loans are repaid in small, weekly installments. The installments are collected by a bank worker in a meeting of the "loan center" (a collection of approximately six to eight groups, each of which has five members). The repayment of the loan in weekly installments makes it likely that defaulters are identified early in the process of the repayment of the loan, and can be pressured by their peers, as well as by the bank worker, to "keep step" in their loan repayment.

3. Dynamic incentives. Group pressure on defaulters is maximized by the use of two, distinct dynamic incentives: (a) the threat that if any member defaults, his or her peers will not receive loans in the future (mentioned above under the heading of "joint liability"), and (b) loans are sequentially provided to group members. Two of the five members of the group are given the first loans, and their repayment performance is observed for a month or two (Rahman, 1999, p. 7). If their repayment performance is deemed satisfactory, then two more members receive their loans. Finally, if the repayment performance of the previous four borrowers is satisfactory, the fifth member of the group receives his or her loan.

Poor borrowers in developing countries generally lack collateral that can be used to guarantee their loans, and lenders often lack the means to use the legal system to enforce repayment. In such contexts, economists have identified three advantages of group lending over conventional, individual lending: 
- Minimizing the effect of adverse selection. The problem of adverse selection arises in credit provision due to asymmetric information of the prospective borrower's "quality" as a borrower. Borrowers who are likely to succeed in the projects funded by loans, and who are internally motivated to repay their loans, can be called "safe" borrowers; borrowers who lack these characteristics can be called "risky" borrowers. If lenders cannot identify the borrower's type, making it difficult for them to refuse loans to risky borrowers, loan programs will tend to attract risky borrowers who have a relatively high probability of defaulting. Ghatak (1999) and van Tassel (1999) have argued that, if (a) groups are allowed to form themselves, (b) members can make side-payments to each other (such as offers to help in each other's businesses), and (c) borrowers can identify each other's type (even though outside lenders cannot identify borrrowers' types), then safe borrowers will tend to form groups with other safe borrowers, leaving risky borrowers to form groups among themselves. This "positive assortative matching" will enable lenders to screen safe from risky groups using various loan characteristics as instruments.

- Minimizing ex ante moral hazard. Another type of asymmetric information creates an additional problem in the credit market. Borrowers often have private information of the amount of effort they exert in making their projects succeed, or in the specific project they undertake using the borrowed funds. Borrowers, for example, may have a number of alternative projects in which the borrowed funds can be invested. Higher yielding projects may require extra costs and effort that can be saved by using the funds for lower yielding projects (or even using the funds for meeting family obligations like paying off a daughter's dowry). Given that legal means for enforcing repayment and individual collateral are generally lacking in the relevant context, borrowers can profitably shirk by choosing low-yielding and low-effort projects and then claiming that their projects failed, making repayment impossible. Under group lending, this moral hazard problem is minimized, due to the large amount of information that group members have of each other's activities. The absence of asymmetric information within the group solves the moral hazard problem, just as it can aid in solving the adverse selection problem. ${ }^{2}$

- Employing social sanctions to enforce loan commitments. A third ad-

${ }^{2}$ The seminal paper developing this approach is Stiglitz (1990). 
vantage of group lending over individual lending is the ability of the group to enforce loan commitments by using social sanctions (Besley and Coate, 1995). Outside lenders in developing countries, as noted above, often lack the ability to use the legal system to enforce the commitments of borrowers to repay their loans. Fellow group members have a number of powerful tools of enforcement, such as social ostracism and even violent seizing of delinquent borrowers' assets, that can be employed to ensure that loans are repaid.

\section{$2.2 \quad$ Model}

This section presents a simple model of decisionmaking by borrowers in group lending programs, in the presence of moral hazard. ${ }^{3}$ By increasing her level of of (costly) effort, a borrower can increase the probability that her project will succeed. Her effort level, however, is observable to her peers only with probability $\alpha$. The model makes the simplifying assumption that whatever information that group members have of their peers' use of their loans is obtained without members having to make a decision as to how much effort to expend in monitoring their peers; in other words, the information becomes available in an exogenous manner. This assumption is made partly for the sake of simplicity, and partly because any attempt to model the monitoring decision requires assumptions regarding the form of the "production function" of monitoring, and we have no knowledge of the nature of this function. It may be, for example, that there are increasing returns to group size in monitoring, so that the cost of monitoring $n$ peers is less than twice the cost of monitoring $n / 2$ peers. Or the opposite could be the case.

As is standard in the literature, I assume that each borrower can choose between an infinite number of alternative projects, each with its own probability of success $p \in[0, \bar{p}]$, where $\bar{p} \in(0,1)$ is the maximum probability of success attainable. If the project succeeds, the borrower receives a payoff of $v$. Since the probability of success is a monotonically increasing function of the effort exerted by the borrower, we can specify that the cost of

\footnotetext{
${ }^{3}$ Moral hazard is the focus of the model, since, as I have shown elsewhere (Guttman, 2006a), the "positive assortative matching" result underlying the adverse selection approach holds only for a limited range of parameter values. The third approach discussed above, the group enforcement (or "social collateral") approach first proposed by Besley and Coate (1995), is broadly consistent with the alternative approach outlined in Section 4.
} 
undertaking a project $c$ increases with the probability of success: ${ }^{4}$

$$
c=(\beta / 2) p^{2},
$$

where $\beta$ is a positive parameter, measuring the marginal cost of undertaking a relatively safe project. There are $n+1$ members in the group. ${ }^{5}$

Each member receives a loan of size $L$ and pays a gross interest rate $r$. The gross interest rate $r$ includes principal and interest, so that if $r=1$ the net interest rate is zero; if $r=1.2$, for example, the net interest rate is 20 percent. Let borrower $i$ 's expected cost of having to repay fellow members' debts, when at least one of the peers defaults and borrower $i$ 's own project succeeds, be $x$. This variable, which will be calculated below as a function of $n$ and $p$, is expressed as a function of the principal portion of the peers' debts, but each borrower is liable for interest on these debts as well. Note that both the member's repayment of her own loan, and her repayment of peers' loans when they default, are made only if the member's own project succeeds. If the member's project fails, she pays nothing, since she has no collateral. However, as stated above, with probability $\alpha$ the member $i$ 's peers observe her effort level. If this effort level was less than that required to achieve the maximum probability of success $\bar{p}$, the peers impose a social penalty $\left(\bar{p}-p_{i}\right) F$ on the member whose project fails. Thus member $i$ 's expected payoff of taking a loan is ${ }^{6}$

$$
\pi_{i}=p_{i}[v-r(L+x)]-(\beta / 2) p_{i}^{2}-\left(1-p_{i}\right) \alpha\left(\bar{p}-p_{i}\right) F .
$$

${ }^{4}$ The function is quadratic, in order to satisfy the second-order condition for an internal solution for $p$.

${ }^{5}$ In the Grameen Bank, there are two levels of group organization. At the lower, "group" level, there is a fixed number of five members. At a higher level, a number of groups (usually six to eight) are federated in a "loan center." Under the rules of the bank, joint liability is primarily located at the group level, but "If an entire group is dissolved before full repayment of loans, the center shall be liable for all outstanding loans." [Grameen Bank Bidhimala (Constitution), Section 7.3]. There is evidence that, in practice, joint liability is applied on the level of the loan center:

Tara, a center chief in the village, explained the social collateral from her own experience. As a center chief, every week she is not only responsible for paying her own kisti (installment), but she must also make sure that other members in the loan center pay their kisti. The bank gives loans to individual members but puts joint liability on all borrowers in the loan center. (Rahman 1999, pp. 79-80.)

${ }^{6} \mathrm{I}$ assume that $v>r(L+x)$, implying that the member can repay (at least in terms of expected value) her liabilities to the bank if her project succeeds. 
Member $i$ maximizes $\pi_{i}$ by choosing $p_{i}$, i.e., by choosing the project with the optimal probability of success, taking account of the higher cost of choosing chosing projects with relatively high probabilities of success. Differentiating (1) w.r.t. $p_{i}$ and solving for $p_{i}$, we obtain, for the optimal $p_{i}{ }^{7}$

$$
p_{i}^{*}=\min \left[\frac{v+\alpha(1+\bar{p}) F-r(L+x)}{\beta+2 \alpha F}, \bar{p}\right] .
$$

Equation (2) immediately implies that, for an interior solution, the borrower's probability of success, and thus her probability of repaying her loan, decreases as her loan size increases and as her expected liability for her peers' debts increases. The intuition for this result is simply that as the borrower's debt burden increases, her expected payoff of success decreases, thus increasing the incentive to choose projects with a higher probability of failure.

Let us now write out $x$ in terms of $p_{i}, n$, and $p_{j}$, the success probability of agent $i$ 's peers. I assume, as is the case in the programs under study, if even one group member defaults, the remaining members must repay the defaulter's loan. I assume further that the loan sizes and the success probabilities of the other $n$ group members are identical, and that the members' success probabilities are statistically independent. Under these assumptions, the probability that the projects of $s$ out of the $n$ other group members succeed is

$$
\left(\begin{array}{c}
n \\
s
\end{array}\right) p_{j}^{s}\left(1-p_{j}\right)^{n-s}
$$

and therefore

$$
x=\sum_{s=0}^{n-1}\left(\begin{array}{c}
n \\
s
\end{array}\right) p_{j}^{s}\left(1-p_{j}\right)^{n-s} \frac{(n-s) L}{s+1},
$$

since, if $s$ projects succeed, then $n-s$ peers' loans must be repaid by the remaining $s$ peers plus member $i$, whose project succeeds by assumption. Equation (3) simplifies to

$$
x=\left[\frac{1-p_{j}-\left(1-p_{j}\right)^{n+1}}{p_{j}}\right] L .
$$

\footnotetext{
${ }^{7}$ Equation (2) takes account of the possibility of a corner solution, at which the borrower exerts sufficient effort to make her probability of success equal to $\bar{p}$, which would occur when

$$
\frac{v+\alpha F-r(L+x)}{\beta+\alpha F} \geq \bar{p}
$$
}


Since $(1-p)^{n+1}$ decreases monotonically as $n$ increases, we conclude that $x$ will increase monotonically as $n$ increases. Substituting (4) into the expression for member $i$ 's optimal probability of success, for an interior solution, we have

$$
p_{i}^{*}=\frac{v+\alpha(1+\bar{p}) F-\frac{r L\left[1-\left(1-p_{j}\right)^{n+1}\right]}{p_{j}}}{\beta+2 \alpha F} .
$$

Equation (5) implies that, as $n$ increases, for a given $p_{j}$, each borrower's equilibrium probability of success $p_{i}$ will decrease, and therefore her probability of repayment will decrease.

\section{Evidence from Bangladesh}

This section presents a test of the model of Section 2, using data from a survey conducted in 1991-92 by the Bangladesh Institute for Development Studies in collaboration with the World Bank. The survey covered some 1,798 households in 87 villages. The respondents in this survey reported receiving loans from a wide variety of sources, including various non-governmental organizations (NGOs), friends, family, moneylenders, banks, and-most importantly for this study - three microfinance programs. The three microfinance programs were: the Bangladesh Rural Advancement Committee (BRAC), the Bangladesh Rural Development Board (BRDB) RD-12 program, and the Grameen Bank. For the purposes of the empirical work of this study, only loans taken from one of these three programs were included in the analysis, in order to ensure that the observations were from group loan programs. Additionally, the analysis examines only loans that were fully repaid at the time of the survey (but not necessarily repaid at the due date of the loan), so that the degree of arrears (if any) can be calculated. ${ }^{8}$ After observations with missing values for one or more of the variables were deleted, the number of observations was 1,159 .

The dependent variable is (the negative of) the degree of arrears, thus measuring repayment performance. ${ }^{9}$ More specifically, let $\bar{t}$ be the promised

\footnotetext{
${ }^{8}$ Earlier studies (e.g. Godquin 2004, which uses the same data set) have tended to define repayment performance in terms of a binary variable, based on an arbitrary definition of what constitutes repaying "on time" (i.e., a given maximum "grace period" is allowed). The approach chosen here avoids the arbitrariness of the binary approach, and permits using ordinary least squares as the estimation technique. For a previous study which also employs a continuous dependent variable, see Sharma and Zeller (1997).

${ }^{9}$ While the model makes the conventional simplifying assumption that success of the
} 
date of full repayment of the loan, and let $t$ be the date at which the loan was fully repaid. Then the dependent variable is defined as $\bar{t}-t$. Thus, if the dependent variable is negative, the loan was not fully repaid on time, and the larger the variable in absolute value, the greater the degree of arrears. But when a negative number becomes larger in absolute value, it is actually smaller, so that larger values of the dependent variable represent less arrears. If the dependent variable is positive, the loan was fully repaid before the promised date.

The two explanatory variables of greatest interest correspond to hypotheses deriving from the implications of the model:

- The larger the size of the loan, $L$, the less likely the loan will be repaid on time.

- The larger the group size, $n$, the less likely the loan will be repaid on time. ${ }^{10}$

In addition to these two variables, the following control variables were included in the analysis:

Loan duration. The longer the duration of the loan, the more opportunity the borrower has to overcome short-run shocks, which tend to characterize production in rural areas. Thus a positive coefficient is expected for this variable.

Productive purpose. If the stated purpose of the loan was businessrelated, it is relatively likely that the loan will generate an income stream that will allow the loan to be repaid. It must be borne in mind, of course, that many (perhaps most) loans are not utilized for their stated purpose (see Rahman, 1999). Nevertheless, to the extent that the stated purpose of the loan has any usefulness in predicting the actual use of the loan, a positive coefficient would be expected. This variable is a dummy variable taking the value of unity when the stated purpose of the loan was business-related (either agricultural or non-agricultural). For the purposes of the discussion below, let us denote this variable as PRODPUR.

project, and thus repayment, is a dichotomous variable, in reality this is clearly not the case. In testing the model, it is assumed that the higher the probability of success, the closer the date of full repayment will be to the loan's due date, thus justifying the use of a continuous degree of arrears as the dependent variable.

${ }^{10}$ Group size is measured by the number of members of the loan center, since the smaller groups comprising the loan centers have a uniform size of five, at least in the Grameen Bank. As noted fn. 5, in practice joint liability extends to the entire loan center and not only to the members of the group. 
Credit rationing. This variable is defined as the difference between the borrower's optimal loan size, as she reported it in the survey, and the actual loan size. The larger the degree of credit rationing, the more likely that the borrower will have an incentive to repay in order to receive loans in the future. Thus a positive coefficient is expected.

Training period. In the microfinance programs under study, eligibility to receive a loan was conditioned on participation in a training program, in which the values and ideology of the group training approach, as well as the rules of the program, were taught. If these training programs have any effect on repayment performance, we would expect that effect to be positive. Thus the number of weeks during which the borrower participated in a training program is expected to receive a positive coefficient.

Seniority of membership in group. Paxton et al. (2000) suggest that as groups "age," their ability to cooperate declines. While Paxton, et al. (2000) provide some empirical support for this hypothesis, their theoretical argument is not well based on individual optimizing behavior. An alternative explanation is that each borrower has a limited number of investment projects that are optimal to undertake, given the interest rate charged by the lending institution. Upon joining the group, the individual first undertakes her most profitable investment available project, then her next best project, and so forth. With each successive loan, the borrower has fewer additional optimal projects that remain to be undertaken, reducing the present value that she places on her long-run relationship with the lending institution (which is endangered if she defaults, due to the threat of not being refinanced). Thus the borrower's incentive to repay the current loan declines as her seniority in the group increases.

To assess the validity of the above explanation, I utilized a variable in the survey that measures the respondent's optimal loan size, mentioned above in defining the "credit rationing" variable. Borrowers were asked, "How much in total would you borrow at the same rate of interest if there was no limit to the amount you could borrow from [the] same source for the same purpose at that time?" Let us denote this variable $L^{*}$. We can regard this variable as a measure of the value of the loans that the individual would like to obtain in the present and the future from the lending institution. Denote the member's seniority of membership in the group as MEMDUR. If the explanation of the previous paragraph is valid, we would expect $L^{*}$ to be negatively related to $M E M D U R$, particularly in the context of productive investments, i.e., where PRODPUR $=1$. Regressing $L^{*}$ on $M E M D U R$ and 
on PRODPUR*MEMDUR, we obtain

$$
L^{*}=6808.3-10.3 * M E M D U R-23.1 * P R O D P U R * M E M D U R,
$$

where the coefficient of $P R O D P U R * M E M D U R$ is statistically significant at the 0.01 level (two-tailed test) $;^{11}$ the number of observations is 1,484 . This result supports the hypothesis that the member's present value of future loans from the lending institution declines as her seniority in the group increases, particularly when the loan is ostensibly for the purpose of funding a productive investment.

In addition to the variables discussed above, four dummy variables were included in the regression:

- The first two, $B R A C$ and $B R D B$, take the value of unity when the loan program was associated with one of these two lending institutions. (When both variables take the value of zero, the loan program was the Grameen Bank.)

- A third dummy variable, COSIGN, takes the value of unity when the borrower stated that a "signature or personal guarantee" was required in order to obtain the loan. Normally, such cosigning would appear to be inconsistent with group lending, and indeed, in one regression, only observations for which $C O S I G N=0$ were included. Where this variable is included in the regression, it is expected to receive a positive coefficient.

- Finally, the survey gives information on other services provided by the loan program. One such service, the provision of "market information," was found to be significantly related to loan repayment. Thus a dummy variable, MKTINFO, is included, which takes the value of unity when the respondent stated that this service was provided by the loan program.

Table 1 shows the regression results, where the dependent variable is the measure of loan repayment performance described above. The table shows the results for two regressions: (1) a regression including COSIGN as an explanatory variable, and (2) a regression including only observations for which $C O S I G N=0$.

\footnotetext{
${ }^{11}$ The $t$-statistic for $M E M D U R$ is -1.0 , while the $t$-statistic for PRODPUR*MEMDUR is -2.6 .
} 
Repayment Performance in Microcredit Programs: Theory and Evidence 11

Table 1

Regressions of Repayment Performance on Selected Variables

\begin{tabular}{|l|c|c|}
\hline & 1 & 2 \\
\hline \hline Loan size $(L)$ & $\begin{array}{c}-0.00554 \\
(-2.75)^{* *}\end{array}$ & $\begin{array}{c}-0.00735 \\
(-2.48)^{*}\end{array}$ \\
\hline Group size $(n)$ & $\begin{array}{c}1.13 \\
(4.20)^{* *}\end{array}$ & $\begin{array}{c}1.39 \\
(3.69)^{* *}\end{array}$ \\
\hline PRODPUR & -8.79 & 20.4 \\
& $(-0.899)$ & $(1.37)$ \\
\hline Loan duration & 0.682 & 0.682 \\
& $(23.5)^{* *}$ & $(20.5)^{* *}$ \\
\hline Credit rationing & -0.0000438 & -0.000453 \\
& $(-0.086)$ & $(-0.657)$ \\
\hline Training period & 1.54 & 1.20 \\
& $(1.75)$ & $(1.03)$ \\
\hline Seniority of membership & -0.259 & -0.395 \\
& $(-2.13)^{*}$ & $(-2.41)^{*}$ \\
\hline BRAC & -54.3 & -69.8 \\
& $(-5.21)^{* *}$ & $(-4.60)^{* *}$ \\
\hline BRDB & 19.1 & 15.3 \\
& $(2.51)^{*}$ & $(1.52)$ \\
\hline$C O S I G N$ & 8.98 & \\
\hline MKTINFO & $(1.47)$ & \\
\hline Constant & -13.4 & -15.9 \\
\hline $\bar{R}^{2}$ & $(-2.13)^{*}$ & $(-2.12)^{*}$ \\
\hline Number of observations & -238.3 & -256.2 \\
& $(-12.6)^{* *}$ & $(-10.6)^{* *}$ \\
\hline
\end{tabular}

Notes: Estimation method: OLS. T-statistics in parentheses.

*Statistically sig. at 0.05 level. **Statistically sig. at 0.01 level.

Table 1 presents the empirical results. The coefficient of the loan size variable is negative and statistically significant in both regressions, as expected. This coefficient is consistent with the moral hazard model of Section 2. But the coefficient of the group size variable, which was predicted to be negative, turns out to be positive and significant in both regressions. ${ }^{12}$ It

\footnotetext{
${ }^{12}$ For another study that observed a positive effect of group size on repayment perfor-
} 
is this result which leads us to reconsider the moral hazard model, and an alternative approach is presented in Section 4.

Turning to to the other variables, the duration of the loan receives a positive and significant coefficient in both regressions, as expected. The borrower's seniority of membership in the group receives a negative and significant coefficient in both regressions, as expected. Repayment performance in the BRAC program was significantly lower than in the Grameen Bank, while repayment performance in the BRDB program was significantly higher according to regression 1 , but this coefficient is not quite significant in regression 2. MKTINFO receives negative and statistically significant coefficients in both regressions. While this result is somewhat unexpected, it can be interpreted as indicating the negative effect of exposure to alternative loan sources on repayment performance (by weakening the refinancing threat), which may accompany availability of additional market information. The remaining variables do not receive statistically significant coefficients.

\section{An Alternative Approach}

The empirical result that group size is positively related to repayment performance directly contradicts the moral hazard model, as noted above. This section presents an alternative approach which explains the positive effect of group size, and is consistent with the other empirical results as well.

The moral hazard model developed in Section 2 assumes that members whose projects succeed repay their loans, either due to their interest in continuing to receive loans from the lending institution, or due to social pressure from their peers. If a member's project fails and she exerted less than the maximal level of effort, the model assumes that she is punished by her peers with probability $\alpha$. The approach to be developed in this section assumes that $\alpha F$ is sufficiently large to drive the borrower into a corner solution at which she chooses the maximal level of effort in her investment project (which has a probability of success $\bar{p}$ ). ${ }^{13}$ There remains a positive probability $1-\bar{p}$ that she will default due to exogenous shocks such as crop

mance, see Zeller (1998). In other empirical studies, the observed effect was not statistically significant.

${ }^{13}$ The account of Rahman (1999) suggests that loans are often used for purposes other than the stated purpose of productive investments. The alternative approach can accomodate this fact by assuming that if the borrower manages to repay her loan installments, e.g. by borrowing from friends and relatives, she is not punished. The borrower is then assumed to make sure that such funds will be available, in the case that the loan was not used for its stated purpose. 
failure, adverse changes in input or output prices, illness, etc., and this "exogenous" failure is recognized as such by her peers. This requires, of course, that members' information of each other's project choices and effort levels is good enough to distinguish between "exogenous" and "endogenous" project failure. The anthropological study of Rahman (1999) of a village in Bangladesh, many of whose residents receive loans from the Grameen Bank, provides evidence that members' information is indeed sufficiently complete to make such distinctions, as suggested by the following anecdote:

Soon after the start of my fieldwork in the village, many informants (primary and secondary) told me that Ali, one of the first Grameen borrowers, had appropriated a large amount of money from a joint project loan fund of his center and used it to pay dowries for his daughters. Ali always denied the allegation and maintained that the joint project failed because of the dramatic drop of the market price of mustard seeds, which the project bought and stored for profit. As he is treasurer of the joint project, everyone blames him. (p. 93)

When default is due to opportunistic behavior by the defaulter, social sanctions are assumed to be sufficiently strong to prevent default. Rahman (1999) gives several examples indicating the strength of such sanctions, including cases in which defaulting members and their families fled from the village when they were unable to repay. In the words of one of Rahman's informants, Vanu,

When a woman fails to make her installments on time, ${ }^{14}$ she experiences humiliation through verbal aggression from peers and bank workers in the loan center. Such humiliation of women in a public place gives males in the household and in the lineage a bad reputation [durnam]. In an extreme case peers may take the defaulter to the bank office. For a man, if he is locked inside the bank building for several days, it would mean almost nothing to other people in the village. But if this happens to a woman, then it will bring durnam to her household, lineage, and village. People in other villages will also gossip about it.

Rahman continues (p. 75),

\footnotetext{
${ }^{14}$ It should be noted that the vast majority of Grameen Bank borrowers are women.
} 
To make her point, Vanu spoke anecdotally of an occurrence in the neighboring Grameen Bank branch. Vanu heard that one woman in that branch failed to pay her loan installments for a few weeks and she was brought to the bank office by her loan group peers. The bank workers asked this woman to sit in a room in the bank and they locked the door from the outside. Vanu reported that the woman felt so humiliated (oppoman-itohoy-se) that she hanged herself from the ceiling fan...

Given the strength of such sanctions in Bangladesh, it seems reasonable to assume that borrowers will generally make every effort to repay (which may involve taking informal loans from relatives and friends), and default will usually be due to exogenous shocks. ${ }^{15}$ Failure by the group to repay, then, can result from one of two causes: (1) the "exogenous shocks" impact on a sufficiently large proportion of group members, making repayment infeasible, or (2) since repayment by the group is a public good to the group members (each member benefits from continued credit from the bank, whether or not she helps to repay the debts of defaulters), a free-rider problem may prevent raising the required funds.

It can be shown that Nash equilibria exist in which the required funds will raised if such funds are available to the successful group members, provided that the benefit of continued credit to each member is greater than the cost of lending funds to defaulters to permit them to repay their installments. This point can be illustrated by examining the case of two successful members and one defaulter (the analysis can be extended to any number of members). Let the installment that the defaulter must pay the bank be $\bar{\ell}$. Suppose that the cost to successful member $i(i=1,2)$ of lending the sum $\ell_{i}$ to the defaulter in order to allow her to repay is $\gamma \ell_{i}$, where $\gamma \in(0,1)$ is a parameter reflecting each successful member's discounting of the defaulter's future repayment of her debt to the successful member, which may be due to the difficulty of charging interest to the defaulter, as well as the risk of default. Denote each successful member's present value of continued credit from the bank as $z$. Then if $z>\gamma \ell_{i}$ for each successful member $i$, there are an infinite number of pure strategy Nash equilibria in which the two successful members cooperate to lend the required sum $\bar{\ell}$, one equilibrium for any pair $\left(\ell_{1}, \ell_{2}\right)$ such that $\ell_{1}+\ell_{2}=\bar{\ell}$, assuming that each successful member $i$ has sufficient funds to lend $\ell_{i}$. This can be seen by inspecting the payoff matrix in Table 2 , constructed for an arbitrary pair $\left(\ell_{1}, \ell_{2}\right)$.

\footnotetext{
${ }^{15}$ This is broadly consistent with the "social collateral" approach of Besley and Coate
} (1995), as noted above. 
Table 2. Payoff Matrix for Game Between Two Successful Members

\begin{tabular}{|c|c|c|}
\hline & Lend to Defaulter & Don't Lend \\
\hline Lend to Defaulter & $z-\gamma \ell_{1}, z-\gamma \ell_{2}$ & $-\gamma \ell_{1}, 0$ \\
\hline Don't Lend & $0,-\gamma \ell_{2}$ & 0,0 \\
\hline
\end{tabular}

In the cells where one successful member lends to the defaulter and the other does not lend, the lender pays the cost $\gamma \ell_{i}$ and receives no benefit, since the required funds are not repaid to the bank and the bank refuses to lend in the future to the group. When both successful members refuse to lend to the defaulter, they both receive payoffs of zero (no benefit and no cost). If both members lend to the defaulter, each receives a payoff of $z-\gamma \ell_{i}$, which is positive, by assumption. There are two Nash equilibria in pure strategies in this game: (1) both successful members lend to the defaulter and the bank is repaid, and (2) both successful members refuse to lend to the defaulter, and the group defaults.

The Pareto-preferred equilibrium, of course, is the one in which both successful members lend to the defaulter. Thus the only problem facing the pair of successful members is to coordinate on this Pareto-preferred equilibrium. Assuming that this coordination problem can be solved, group default will occur if and only if exogenous shocks prevent repayment by a sufficiently large proportion of group members, such that the successful members are incapable of lending to the unsuccessful members the funds that would allow them to repay the bank.

Let us calculate the probability that the successful group members will have sufficient funds to lend to the unsuccessful members, thus preventing default by the group. Let $s$ denote the number of successful members, i.e., the members whose projects succeed. Suppose each successful member can lend $y$ to the unsuccessful members. Then, in order for the successful members to be able to lend sufficient funds to the unsuccessful members, we require $s y \geq(1-s) \bar{\ell}$. Solving for $s$, we obtain the critical proportion of successful members required to prevent group default, which we denote as $k$ :

$$
k=\frac{\bar{\ell}}{y+\bar{\ell}} .
$$

The probability that at least the proportion $k$ of the projects of the group membership $n+1$ will succeed is

$$
P=\sum_{s=\lceil k(n+1)\rceil}^{n+1} \bar{p}^{s}(1-\bar{p})^{n+1-s}\left(\begin{array}{c}
n+1 \\
s
\end{array}\right),
$$




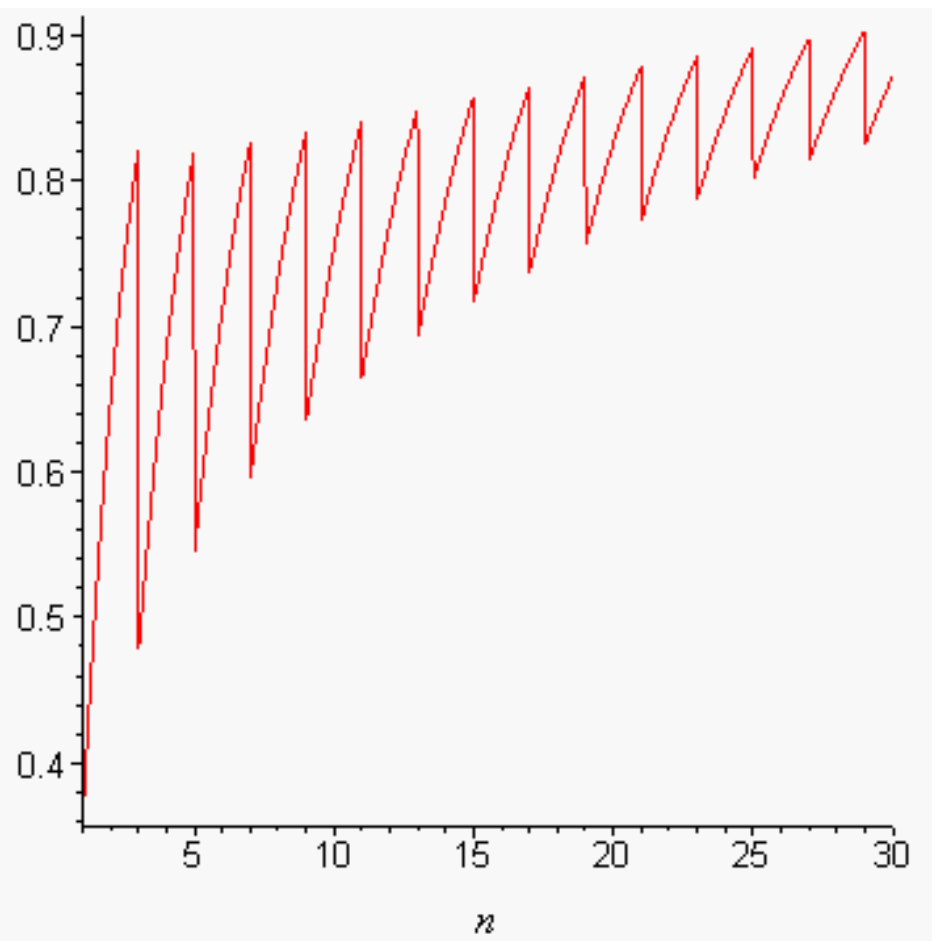

Figure 1: Probability of Group Repayment as Function of Group Size

where $\lceil k(n+1)\rceil$ is the smallest integer at least equal to $k(n+1)$. While the effect of $n$ on $P$ cannot be derived analytically, we can observe the effect by numerical methods. Figure 1 shows $P$ as a function of $n$ when $\bar{p}=0.6$ and $\bar{\ell}=y$, implying that $k=0.5$. The "choppy" quality of the graph is due to the fact that the summation is performed over integer values for $s$.

Similar graphs are obtained for other values of $p$ and $k$, provided only that $k$ is no higher than a critical level which is greater than 0.5. (Previous theoretical studies have implicitly assumed that $k \leq 0.5$, since groups of only two or three members were considered, and the successful member has been assumed to be able to cover the debt of the unsuccessful member/s.)

Thus the approach outlined here can easily explain the observed positive effect of group size on repayment performance. The negative effect of loan size on repayment performance can also be explained, since a larger loan size implies a larger $\bar{\ell}$, thus (for a given $y$ ) increasing $k$, the required proportion of successful members, which will reduce $P$. The remaining empirical results 
concern control variables, and are not specifically related to either the moral hazard model or the alternative approach.

\section{Concluding Remarks}

This paper has revisited the theoretical and empirical literature on repayment performance in microcredit programs. We found that one of the dominant approaches to explaining the success of microcredit, namely the moral hazard approach, does not seem to accord well with one statistically significant empirical result: the positive effect of group size on repayment performance. An alternative approach, which is more closely related to the "social collateral" theory of Besley and Coate (1995), predicts this positive effect, and is consistent with the other empirical results that were obtained.

It should be noted that the social collateral approach works well in the context of Bangladesh, but might work less well in other cultural contexts, where group members may be less willing to apply social sanctions on delinquent borrowers. A second caveat, in the juxtaposition of the moral hazard model and the empirical results, is that the present development of that model assumed that $\alpha$, the probability of detection of shirking, is invariant to group size. If, in a more realistic moral hazard model, $\alpha$ could be shown to increase with group size, such a model could also explain a positive effect of group size on repayment performance. Given that monitoring of peers by group members is a public good for the group, however, it does not seem likely that an unambiguous positive effect of group size on $\alpha$ could be obtained in such models, without making special assumptions about the "production function" of monitoring.

\section{References}

Besley, T., and Coate, S., 1995. Group lending, repayment incentives, and social collateral. Journal of Development Economics 46, 1-18.

Ghatak, M., 1999. Group lending, local information, and peer selection. Journal of Development Economics 60, 27-50.

Ghatak, M. and Guinnane, T.W., 1999. The economics of lending with joint liability: Theory and practice. Journal of Development Economics $60,195-228$.

Godquin, M., 2004. Microfinance repayment performance in 
Repayment Performance in Microcredit Programs: Theory and Evidence 18

Bangladesh: How to improve the allocation of loans in MFIs. World Development 32, 1909-26

Guttman, J.M., 2006. Assortative matching, adverse selection, and group lending. Working Paper 2006-WP-07. Networks Financial Institute, Indianopolis, IN.

Guttman, J.M., 2006. Repayment performance in group lending programs: A survey. Working Paper 2006-WP-01, Networks Financial Institute, Indianapolis, IN.

Morduch, J., 1999. The microfinance promise. Journal of Economic Literature 37, 1569-1614.

Paxton, J., Graham, D., and Thraen, C., 2000. Modeling group loan repayment behavior: New insights form Burkina Faso. Economic Development and Cultural Change 48, 639-55.

Rahman, A. Women and Microcredit in Rural Bangladesh: Anthropological Study of the Rhetoric and Realities of Grameen Bank Lending. (Boulder, CO: Westview, 1999).

Sharma, M. and Zeller, M., 1997. Repayment performance in groupbased credit programs in Bangladesh: An empirical analysis. World Development 25, 1731-42.

Stiglitz, J., 1990. Peer monitoring and credit markets. World Bank Economic Review 4, 351-66.

van Tassel, E., 1999. Group lending under asymmetric information. Journal of Development Economics 60, 3-25.

Zeller, M., 1998. Determinants of repayment performance in credit groups: The role of program design, intragroup risk pooling, and social cohesion. Economic Development and Cultural Change 46, 599-620. 